unplanned clearance for farming and of devastation, and exploitation goes steadily on. At one time no thought was given to its conservation as forest, and various arguments were put forward which contributed towards its neglect. Impossibility of regenerating some of the species was one which is now being proved to be without foundation. The main contributing factor was probably the ease and assumed success with which the early exotic plantations were begun. Ironically, one authority has said recently that "the indigenous forest will serve to tide over any crisis arising out of the destruction of the exotic plantations by widespread epidemics of insects and disease".

Immense areas of the natural forests on the mountainous watersheds of the major rivers have been devastated. Browsing by animals in these areas leads to loss of tree cover followed by erosion and devastating flooding in the rich settled lowland country. In a vast area of more than two million acres of ratakamaki protection forest in the South Island, disastrous results of browsing by opossums, deer and chamois are predicted. In the Waimakariri River catchment area sheep are "slowly making a desert land by close cropping of vegetative cover and expos ing the soil to erosion", and threatening the city of Christchurch with possible catastrophe by floods.

The division of protection forestry of the service is responsible for the control of noxious animals, on which nearly $£ 312,000$ was spent during the year. In official operations during the year 31,494 deer, 24,830 goats and 4,920 chamois were killed and it is claimed that a bounty was paid in respect of $1,106,000$ opossums destroyed.

Not all the new exotic plantations have been made on deep volcanic soils. In one forest in South Island an area of 3,500 acres was blown over by wind on a shallow soil, where, owing to rooting difficulties, the trees appear to be unable to stand after reaching a height of $50 \mathrm{ft}$. This sort of thing is also very liable to happen in Great Britain.

The New Zealand report faces up to another forestry problem, namely, that of putting timber grown in remote areas on the market. The costs have been found to be so high that they are used as a strong argument that farmers and others should grow trees nearer centres of consumption and should exploit and convert them there. This runs counter, however, to any policy which seeks to establish, or maintain, a healthy rural population.

The future of forestry in New Zealand is looking more hopeful for two main reasons. The first is that forest management, though still very backward when compared with some European countries, is being given more attention. Management plans, which are "forest regulations prescribing the application of certain sylvicultural rules, and the execution of certain works to produce a definite result", now apply to no less than $3,080,000$ acres of the indigenous forest. The definition of the objects for which each forest is to be managed is a matter of vital importance and the progress made recently is heartening.

The second reason is that great stress is at last being laid on the need for research in forestry. There is now a large staff of workers so engaged, and the Forest Research Institute at Rotorua publishes its own report, which is rather voluminous, and describes work on a wide variety of subjects. It is gratifying to see that attention since 1956 has been directed to the study of the indigenous forest, which may be a dangerous concept, but is a very significant reality in New Zealand, from which very important lessons can be learnt.

\title{
THE CASE FOR A NEW PROFESSION"EMBRACING SCIENCE, LIBRARIANSHIP AND FOREIGN LANGUAGES
}

\begin{abstract}
A SURVEY*, supported by the National Science A Foundation and sponsored by the Modern Language Association of America, and carried out under sub-contract with the latter Association as part of a contract with the United States Office of Education, Department of Health, Education and Welfare, argues the case for a new profession concerned with the handling of scientific information, librarianship and foreign languages. Its six chapters delineate first the characteristics of this new profession and the influences which have determined its emergence; the snares and problems of recruitment; undergraduate and graduate education in relation to the supply of such recruits; professional training; and the nature of the professional support which is required, in which connexion the authors recommend establishment of an advisory board to devise an appropriate well co-ordinated programme of courses, seminars, research groups or short-time institutes for training those already engaged in the profession or proposing to enter it. There are numerous detailed recommendations, many of which are applicable in Great Britain also, but although Messrs. L. Cohen

* Science Information Personnel: The New Profession of Information Combining Science, Librarianship and Foreign Language. By Leonard Cohen and Kenneth Craven. Pp. vi +74 . New York Science Information, P.O. Box 624, Radio City Station, 1961.) 1.50
dollars.
\end{abstract}

and $K$. Craven lean towards the formation of a professional body, they are not explicit on the point and do not recognize the difficulties inherent in the presence of corporate bodies and individual practitioners which have, in Great Britain, considerably hindered the development of a really strong and representative professional qualifying body.

Some of the recommendations are directed towards management, for example, those relating to salary structure, status and standards. The contribution of the scientist is recognized in recommendations relating to co-operation and mutual understanding between scientists as such and those engaged in information work. Recommendations relating to undergraduate facilities stress the importance of at least two foreign languages, a broad liberal arts education and a major course in a scientific discipline for those entering on scientific information work. Establishment of a graduate school of science information leading to a master's degree is recommended as well as research leading to the establishment of a doctoral programme in this field and the growth of specialized information centres at the universities. They also recommended that technical institutions should explore the needs of industry and government for technicians in special libraries and science information centres and offer appropriate 
curricula, covering such subjects as machine searching, operation of related communication and retrieval instruments, routine indexing and coding tasks.

While the survey anticipates recognition of a more systematic and integrated approach to the organization of scientific information and the according of professional status to the scientific information specialist, the practical difficulties which the implementation of its recommendations are likely to encounter, for example, in regard to teaching staff, at least in the United Kingdom, are scarcely faced. There is also much preliminary work to be done by those already working as information officers and librarians in this field before an appropriate professional body could be formed. Nevertheless, much already exists to form the basis, and the development of the National Lending Library for Science and Technology and of the National Reference Librarv of Science and Information should stimulate the support and organization of research experiment and development into the nature and techniques of communication, the information requirements of scientists, the nature of technical literature sources, manual and mechanical information systems and devices, and the organization and dynamics of information facilities, which the authors of this survey both urge and expect.

\title{
DISTRIBUTION OF BRIGHTNESS IN EXTRAGALACTIC RADIO SOURCES
}

\author{
By A. T. MOFFET and P. MALTBY \\ California Institute of Technology, Pasadena
}

\begin{abstract}
S part of a continuing programme of angular size and brightness distribution measurements, we have observed 180 radio sources with the variable spacing interferometer at the Owens Valley Radio Observatory. In this article we report our results for a group of 88 sources which have been observed with both an east-west and a north-south baseline. All observations were made at a wave-length of $31.3 \mathrm{~cm}$. Some preliminary results of the east-west observations were reported by Bolton ${ }^{1}$.
\end{abstract}

The instrument has been described by Read ${ }^{2}$, and consists of two equatorially mounted $90-\mathrm{ft}$. paraboloids, which can be moved along railroad tracks to certain fixed observing stations. When these observations were taken, there were stations at spacings of $200 \mathrm{ft}$., $400 \mathrm{ft}$., $800 \mathrm{ft}$. and 1,600 ft. east and north of a central junction. With one antenna at the central junction and the other at each of these stations successively, a primary set of observations was made, at transit, of the apparent intensities and positions of the sources. From these observations the amplitude and phase of the complex visibility function ${ }^{3}$ for each source in the east-west and north-south directions were deduced. A secondary set of intensity measurements was taken off the meridian at each spacing in order to obtain supplementary information about the behaviour of the visibility function at other spacings or directions. The distribution of brightness of a source is related to its visibility function by a Fourier transformation ${ }^{8}$. The primary observations may be considered to be somewhat the same as observing the source with two fan beams, each having dimensions of about $2 \times 50 \mathrm{~min}$. of arc.

With a maximum antenna spacing of 1,557 wavelengths, we were able to distinguish details of source structure larger than about $1 \cdot 5^{\prime}$. For a source with diameter between $0 \cdot 6^{\prime}$ and $1 \cdot 5^{\prime}$, an estimate of the diameter was possible, and this was taken to be the width at half-brightness of the circular Gaussian model which fitted best the observed visibility function. The structure of a larger source was determined by comparing the observed portion of the visibility function with artificial visibility functions, calculated for a number of physically reasonable models.

It was found that the majority of the sources greater than $1 \cdot 5^{\prime}$ in extent could not be interpreted as simple, symmetrical sources in which the brightness decreased monotonically from a single peak. About 10 per cent of all the sources were found to fit a model with two equal centres of emission. Of these, Cygnus $A$ is the classic example. These sources are listed in Table 1.

Table 1. Sourors oonsisting of Two Equar Components

$\begin{array}{lc}3 C-75 & N G G 5128 \\ 3 C-111 & \text { (centre source) } \\ 3 C-134 & 3 C-310 \\ 3 C-219 & \text { Cygnus } A \\ 3 C-270 & 3 C-445\end{array}$

The results of the interpretation are shown in Table 2. About half the well-resolved sources were asymmetrical and could be interpreted either as consisting of two unequal components or as single asymmetrical distributions. Comparing the east-west and north-south observations, we found that these sources were usually quite elongated, with a ratio of major to minor axes of $>2: 1$. The remaining one hundred sources, which we have observed only along one baseline, seem to be distributed among the various classifications in more or less the same proportions as those reported in Table 2.

Table 2. NUMBers of SOURCES OF DIFPRRENT TYPes. DIAMETERs REFER TO A CIRCULAR GAUSSIAN MODEL

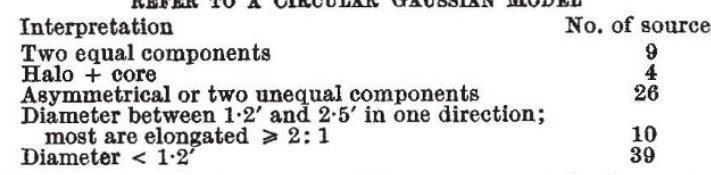

We suggest that many of the asymmetrical sources really consist of two unequal components. To obtain further proof of this, it will be necessary to take observations with a smaller effective beam-width than that used in this work. At large antenna spacings, the visibility function of a source with two well-separated, unequal components will differ markedly from that of a source with a single asymmetrical distribution of brightness. Long baseline observations made at Jodrell Bank ${ }^{4}$ tend to support our suggestion.

We have considered the possibility that the double radio sources may be connected with double, interacting galaxies, as is the case in Cygnus $A$. A number of identifications of radio sources with optical objects has been reported ${ }^{1,5,6}$. Comparing these results with our own, we find that there is not a clear correlation between double radio sources and double galaxies. 